\title{
Optimal Cost of Irrigation Network Design using Epanet
}

\author{
Shikha Arora \\ PG student at Amity University Noida
}

\author{
Anant Kr. Jaiswal \\ Prof. at Amity University Noida
}

\begin{abstract}
An irrigation system is a hydraulic infrastructure that conveys water from the source to the consumers. The aim of the irrigation network design is to find the optimal pipe diameter for each pipe in the network for a given layout, demand loading conditions, and an operation policy. In this paper, we propose a model that uses Genetic Algorithm as an optimization scheme and link this algorithm with Epanet network solver to identify the least cost of pipes used in irrigation systems. Genetic Algorithm, being evolutionary, identifies the pipe diameters in a way that the total cost of the network so obtained, will be minimum. Our model selects the optimal pipe sizes in the final network satisfying all implicit constraints (e.g. conservations of mass and energy), and explicit constraints (e.g. pressure head and design constraints). The hydraulic constraints, deal with hydraulic head at certain nodes to meet a specified minimum value. If the hydraulic head constraint is violated, the penalty cost is added to the network cost.
\end{abstract}

\section{Keywords}

irrigation, Genetic Algorithm, Epanet, optimization, Network cost, penalty cost.

\section{INTRODUCTION}

An irrigation system is a hydraulic infrastructure that conveys water from the source to the consumers; it consists of elements such as pipes, valves, pumps, tanks and reservoirs. The most important consideration in designing and operating an irrigation system is to satisfy consumer demands under a range of quantity and quality considerations during the entire lifetime for the expected loading conditions.

\section{PROBLEM FORMULATION}

The aim of the irrigation system network design is to find the optimal pipe diameter for each pipe in the network for a given layout, demand loading conditions, and an operation policy. Our model selects the optimal pipe sizes in the final network satisfying all implicit constraints (e.g. conservations of mass and energy), and explicit constraints (e.g. pressure head and design constraints). If the hydraulic head constraint is violated, the penalty cost is added to the network cost. However, diameter constraints enforce the evolutionary algorithms to select the trial solution within a predefined limit. The hydraulic information obtained from network solver is then passed to the GA for the computation of fitness of the design. The fitness of a trial solution representing a pipe network design is based on the hydraulic performance of the network. It consists of two parts: (1) network cost; and (2) penalty cost.

The network cost is calculated as the sum of the pipe costs where pipe costs are expressed in terms of cost per unit length. Total network cost is computed as follows:

\author{
$\mathrm{N}$ \\ $\mathrm{C}=\Sigma \mathrm{c}_{\mathrm{k}}\left(\mathrm{D}_{\mathrm{k}}\right) \mathrm{L}_{\mathrm{k}}$ \\ $\mathrm{K}=1$
}

where $c_{k}\left(D_{k}\right)=$ cost per unIt ıength of the kth pipe with diameter $D_{k}, L_{k}=$ length of the kth pipe, and $\mathrm{N}=$ total number of pipes in the system.

The penalty cost is based on the degree of pressure head violation. The penalty functions may be defined, as

$$
\mathrm{C} 1=\mathrm{P}^{*} \mathrm{C}_{\max } * \operatorname{Max}\left(\mathrm{H}_{\min }-\mathrm{H}_{\mathrm{i}}\right)
$$

if the pressure is less than minimum limit and greater than zero; or

$$
\mathrm{C} 1=2 * \mathrm{P} * \mathrm{C}_{\max }-2 * \mathrm{C}
$$

if the pressure is less than or equal to zero.

In above two equations, $\mathrm{P}$ is the penalty cost coefficient, $\mathrm{Cmax}$ is the maximum possible cost that is calculated based on the largest commercial pipe available, (Hmin- $\mathrm{Hi})$ is the maximum pressure deficit, and $\mathrm{C}$ is the actual network cost. The maximum pressure deficit is the difference between the required head (Hmin) at each node and the head found after simulation (Hi). If the pressure head is greater than the minimum required limit, no extra cost is charged to the network cost.

The mathematical formulation of water distribution network can thus be stated as follows:

Minimize Cost $\mathrm{C}=$ Network cost + Penalty cost

Subjected to:

$\mathrm{G}(\mathrm{H}, \mathrm{D})=0$, a conservation of mass and energy equation

$\mathrm{H}_{\mathrm{i}} \geq \mathrm{H}_{\mathrm{i}}$ min nodal pressure head bounds

$\mathrm{D}_{\text {min }}<\mathrm{D}(\mathrm{k})<\mathrm{D}_{\max }$, constraints related to design parameters where,

$\mathrm{H}_{\mathrm{i}}=$ pressure head at node $\mathrm{i}$,

$\mathrm{H}_{\mathrm{i}} \min =$ minimum head required at the same node,

$\mathrm{D}(\mathrm{k})=$ decision variables (pipe sizes).

\section{PROPOSED SOLUTION THROUGH GENETIC ALGORITHM}

Here we attempt to solve the problem using genetic algorithms (GAs), an evolutionary optimization technique. GAs is founded as a randomized search and optimization technique based on Darwin's theory of the "survival of the fittest" and a stochastic information exchange procedure .

\subsection{Outline of the Basic Genetic Algorithm}

3.1.1. [Start] Generate random population of $n$ chromosomes (suitable solutions for the problem). 
3.1.2. [Fitness] Evaluate the fitness $f(x)$ of each chromosome $x$ in the population.

3.1.3. [New population] Create a new population by repeating following steps until the new population is complete.

3.1.4. [Selection] Select two parent chromosomes from a population according to their fitness (the better fitness, the bigger chance to be selected).

3.1.5. [Crossover] With a crossover probability cross over the parents to form a new offspring (children). If no crossover was performed, offspring is an exact copy of parents.

3.1.6. [Mutation] With a mutation probability mutate new offspring at each locus (position in chromosome).

3.1.7. [Accepting] Place new offspring in a new population.

3.1.8. [Replace] Use new generated population for a further run of algorithm.

3.1.9. [Test] If the end condition is satisfied, stop, and return the best solution in current population.

3.1.10. [Loop] Go to step 2

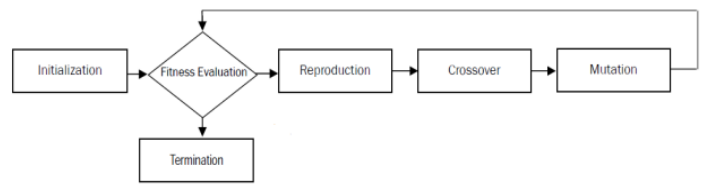

Fig. 1: GA Procedure

\section{INTRODUCTION TO EPANET}

EPANET is a computer program that performs extended period simulation of hydraulic and water quality behaviour within pressurized pipe networks. A network consists of pipes, nodes (pipe junctions), pumps, valves and storage tanks or reservoirs. EPANET is designed to be a research tool for improving our understanding of the movement and fate of drinking water constituents within distribution systems.

\subsection{Steps in Using EPANET}

One typically carries out the following steps when using EPANET to model a water distribution system:

4.1.1. Draw a network representation of your distribution system or import a basic description of the network placed in a text file.

4.1.2. Edit the properties of the objects that make up the system.

4.1.3. Describe how the system is operated.

4.1.4. Select a set of analysis options.

4.1.5. Run a hydraulic/water quality analysis.

4.1.6. View the results of the analysis.

\section{WORKING MECHANISM}

5.1 With the help of EPANET draw a network. Set all the necessary parameters.

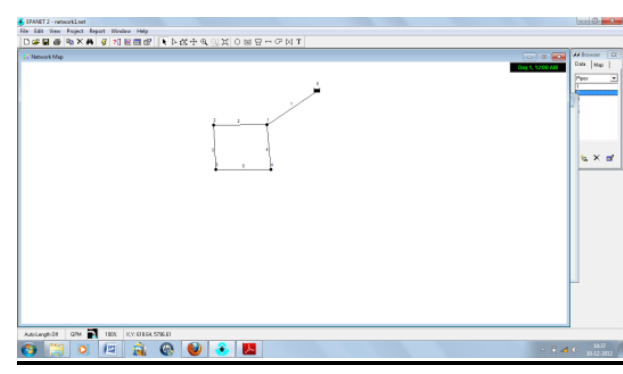

Fig. 2 : EPANET network

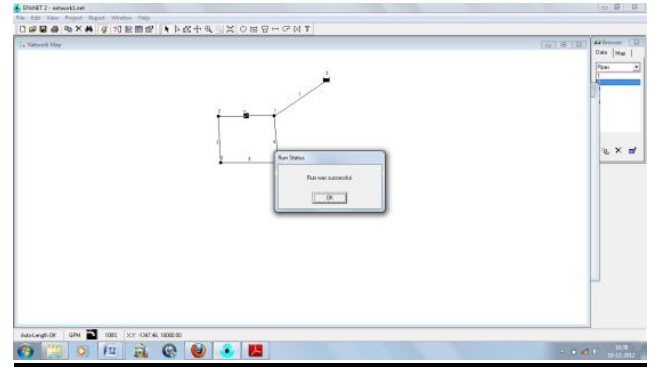

Fig. 3 : Execution of EPANET

5.2. The randomly generated population is serving as pipe diameter that is used in the network. Run EPANET and measure nodal pressure for each set of diameter. This pressure deficit is then use to calculate the penalty cost.

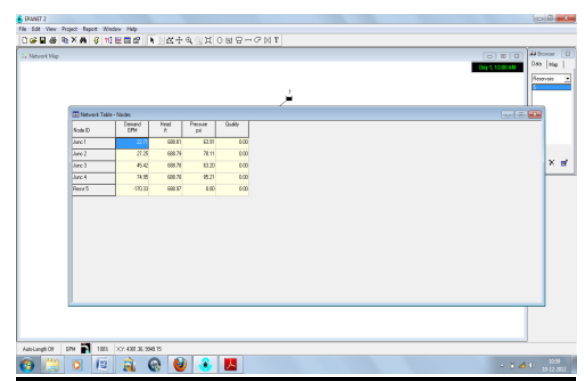

Fig. 4 : Result table of Pressure at every node

\section{RESULT AND ANALYSIS}

The results for the optimization of irrigation system network are evaluated using EPANET. Genetic Algorithm is applied in conjunction with EPANET to find optimum results.

For cost per unit diameter it uses commercially available pipe sizes. 
TABLE 1- COST DATA FOR PIPES

\begin{tabular}{|c|c|c|}
\hline Diameter (In) & Diameter(Mm) & Cost \\
\hline 1 & 25.4 & 2 \\
\hline 2 & 50.8 & 5 \\
\hline 3 & 76.2 & 8 \\
\hline 4 & 101.6 & 11 \\
\hline 6 & 152.4 & 16 \\
\hline 8 & 203.2 & 23 \\
\hline 10 & 254.0 & 32 \\
\hline 12 & 304.8 & 50 \\
\hline 14 & 355.6 & 60 \\
\hline 16 & 406.4 & 90 \\
\hline 18 & 457.2 & 130 \\
\hline 20 & 508.0 & 170 \\
\hline 22 & 558.8 & 300 \\
\hline 24 & 609.6 & 550 \\
\hline
\end{tabular}

In this case a simple network optimization is performed. The network has 4 node, one reservoir (water supply mean) and 5 pipes.

Following are the EPANET parameters in case 1:

Minimum pressure requirements $=60.00 \mathrm{psi}$

Cmax $=2750000$

Penalty coefficient $=0.004$

TABLE 2- PIPE PROPERTY OF EACH PIPE IN SAMPLE NETWORK

\begin{tabular}{|c|c|c|}
\hline $\begin{array}{c}\text { Pipe } \\
\text { Id }\end{array}$ & Length(M) & Roughness \\
\hline $\mathbf{1}$ & 1000 & 130 \\
\hline $\mathbf{2}$ & 1000 & 130 \\
\hline $\mathbf{3}$ & 1000 & 130 \\
\hline $\mathbf{4}$ & 1000 & 130 \\
\hline $\mathbf{5}$ & 1000 & 130 \\
\hline
\end{tabular}

\section{TABLE 3- DEMAND AND ELEVATION AT EACH NODE}

\begin{tabular}{|c|c|c|}
\hline Node & Demand(GPM) & Elevation(Feet) \\
\hline Node 1 & 22.71 & 541.33 \\
\hline Node 2 & 27.25 & 508.53 \\
\hline Node 3 & 45.42 & 542.93 \\
\hline Node 4 & 74.95 & 492.12 \\
\hline Reservoir & N/A & 688.97 \\
\hline
\end{tabular}

Data Input: data is to be inputted to the EPANET. It contains the possible set of diameters generated by GA. Then calculate result that is the pressure at each node.

\section{TABle 4- RANDOMLY TAKEN PIPE DIAMETERS}

\begin{tabular}{|c|c|c|c|c|c|}
\hline $\begin{array}{l}\mathbf{N} \\
\text { O. }\end{array}$ & $\begin{array}{c}\text { Pipe1 } \\
\text { Diamete } \\
\text { r(in) }\end{array}$ & $\begin{array}{c}\text { Pipe2 } \\
\text { Diamete } \\
\text { r(in) }\end{array}$ & $\begin{array}{c}\text { Pipe3 } \\
\text { Diamete } \\
\text { r(in) }\end{array}$ & $\begin{array}{c}\text { Pipe4 } \\
\text { Diamete } \\
\text { r(in) }\end{array}$ & $\begin{array}{c}\text { Pipe5 } \\
\text { Diamete } \\
\text { r(in) }\end{array}$ \\
\hline 1 & 12 & 10 & 16 & 14 & 20 \\
\hline 2 & 24 & 14 & 8 & 2 & 16 \\
\hline 3 & 2 & 3 & 10 & 8 & 18 \\
\hline 4 & 10 & 18 & 16 & 8 & 12 \\
\hline 5 & 20 & 20 & 8 & 10 & 14 \\
\hline 6 & 3 & 24 & 10 & 20 & 10 \\
\hline
\end{tabular}

Calculate pressure at each node for all possible set of diameters, this pressure helps in calculating penalty cost:

TAble 5- Pressure at EaCh NODE fOR EACh trail in

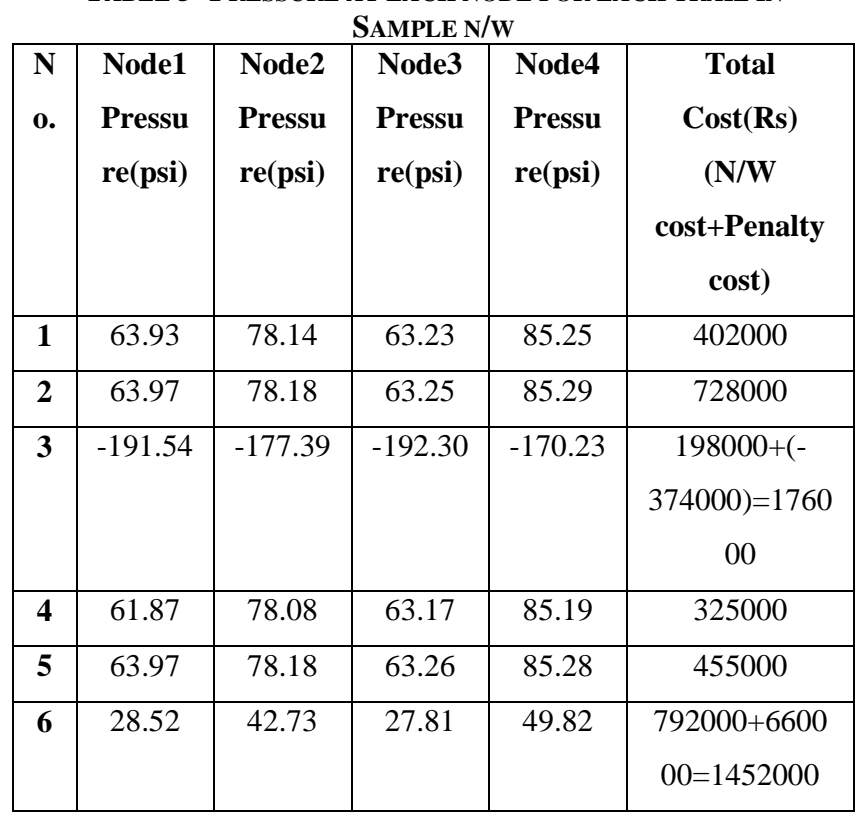

GA will choose two parents at random by "selection". Then after applying crossover and mutation on the randomly generated diameters, the optimum result is obtained after 
applying 5 iterations. Our optimum result is minimum cost of the network.

Optimum result will serve as the final diameter that is to be applied in the EPANET.

\section{CONCLUSION}

Optimal irrigation system network design is a complex task. Various search algorithms have been proposed and attempted. Main concerns are to achieve the optimal solution with the minimum design cost and, at the same time, satisfy the required minimum pressure head at certain demand nodes using only commercially available pipe sizes. In this study Genetic Algorithm, has been coupled with the widely used water distribution network software, EPANET, and applied to water distribution network designs. Hydraulic constraints of the network are satisfied. Penalty cost is very impacting factor in Cost calculation. The main aim of this study is to reduce the penalty cost of the network as much as possible but at the same time our network cost should not be increased so much.

The study shows that GA yields categorically better performance in term of optimal network design cost and/or computational speed. It has been seen that, traditional methods are not capable to design the network required by the time. Traditional heuristics have the limitations with the possible constraints. The proposed genetic algorithm approach can provide the good results with the required constraints.

\section{REFERENCES}

[1] A. Vasan and Slobodan P. Simonovic "Optimization of Water Distribution Network Design Using Differential Evolution". Journal Of Water Resources Planning And Management (C) ASCE / MARCH/APRIL 2010

[2] R. Mohamad Bagher and J. Payman "Water Delivery Optimization Program, of Jiroft Dam Irrigation Networks by Using Genetic Algorithm" Int. J. Advance. Soft Comput. Appl., Vol. 1, No. 2, November 2009 ISSN $2074-$ 8523

[3] Perez-Lopez and Ribas, "Efficient Scheduling Irrigation on Optimization Genetic Algorithms", Journal of Irrigation and Drainage, 312-327. (2007)

[4] Zecchina, Simpsona, Maiera,Leonarda, J. Robertsb, Berrisforda "Application of two ant colony optimisation algorithms to water distribution system optimization". Mathematical and Computer Modelling 44 (2006) 451468
[5] Hossein M. V. Samani and Alireza Mottaghi, "Optimization of Water Distribution Networks Using Integer Linear Programming", J. Hydr. Engrg., Volume 132, (May 2006), Issue 5, pp. 501-509.

[6] D. Naghesh Kumar; K. Srinivasa Raju and B. Ashok, "Optimal Reservoir Operation for Irrigation of Multiple Crops Using Genetic Algorithms". Journal of Irrigation and Drainage Engineering, 123-129. (2006).

[7] M. H. Afshar and M. A. Marino, "A Convergent Genetic Algorithm for Pipe Network optimization", Scientia Iranica, Sharif University of Technology, October 2005, pp. 392-401

[8] Cunha, Ribeiro(2003) "Tabu search algorithms for water network optimization" European Journal of Operational Research 157 (2004) 746-758

[9] Shie-Yui Liong and Md. Atiquzzaman, "Optimal design of water distribution network using shuffled complex evolution" Journal of The Institution of Engineers, Singapore Vol. 44 Issue 12004

[10] Robin Wardlaw and Kampanad Bhaktikul, "Comparison of Genetic Algorithm and Linear Programming Approaches for Lateral Canal Scheduling". Journal of Irrigation and Drainage Engineering, 311-317. (2004).

[11] Eusuff, M.M. and Lansey, K.E.,(2003). "Optimization of Water Distribution Network Design Using the Shuffled Frog Leaping Algorithm." Journal of Water Resources Planning and Management, ASCE, Vol. 129, No. 3, pp. 210-225

[12] Maier, H. R., et al.(2003). "Ant colony optimization for design of water distribution systems." J. Water Resour. Plann. Manage., 129(3), 200- 209.

[13] R.S.V. Teegavarapu and S.P. Simonovic, Optimal Operation of Reservoir System Using Simulated Annealing, Water Resources Management, vol. 16, pp. 401-428, 2002

[14] Wu, Z.Y., Boulos, P.F., Orr, C.H., and Ro, J.E. "Rehabilitation of Water Distribution Systems Using Genetic Algorithms." Journal AWWA, July (2001).

[15] Gupta, I., Gupta, A., and Khanna, P. (1999). "Genetic algorithm for optimization of water distribution systems.", Environmental Modelling \& software Vol.-4, pp. 437-446. 